\title{
Assessment of Sudomotor Function to Predict Future Abnormalities of Glucose Tolerance in at Risk Population
}

\section{A. Ramachandran ${ }^{1}$, A. Moses ${ }^{2}$, C. Snehalatha ${ }^{1}$, A. S. Shetty ${ }^{1}$, A. Catherin Seeli ${ }^{1}$, S. Singvi ${ }^{3}$, JP. Deslypere ${ }^{4}$, P. Brunswick ${ }^{5}$ and JH. Calvet $^{5 *}$}

${ }^{1}$ India Diabetes Research Foundation \& Dr. A. Ramachandran's Diabetes Hospitals, Chennai, India

${ }^{2}$ Moses Diabetes Centre, Chennai, India

${ }^{3}$ Singhvi Clinic, Chennai, India

${ }^{4}$ Aesculape CRO, Singapore

${ }^{5}$ Impeto Medical, Paris, France

\section{Abstract}

Aims: This study done in subjects with an initial normal glucose tolerance (NGT) was to assess the ability of EZSCAN, a new device developed to evaluate sudomotor function, to predict future abnormalities in glucose tolerance.

Methods: South Asian (Indian) subjects ( $n=69,48 \%$ male, mean age $42 \pm 9$ years, mean BMI $\left.28 \pm 5 \mathrm{~kg} / \mathrm{m}^{2}\right)$ diagnosed as NGT with a previous oral glucose tolerance test (OGTT, T0) underwent a frequently sampled OGTT (FSOGTT), 8 months later (T8). At both times EZSCAN tests were done. Using the AUC glucose $_{\text {and } A U C}$ measured by $_{\text {insuin }}$ the FSOGTT, subjects were categorised as normal, high $A_{U C} C_{\text {insulin }}$ or isolated high $A U C_{\text {glucose }}$. Odds ratio (OR) for having high $\mathrm{AUC}_{\text {insulin }}$ or isolated high $\mathrm{AUC} \mathrm{C}_{\text {glucose }}$ vs normal was computed by logistic regression analysis using EZSCAN risk classification at T0 as independent variable $(<50 \%=$ normal, no risk, $50-65 \%=$ intermediate risk and $>65 \%=$ high risk).

Results: At T8, 11 and 5 subjects developed impaired glucose tolerance and diabetes respectively. OR of having high $A U C_{i n s u l i n}$ or isolated high $A U C_{\text {glucose }}$ in the different risk groups was $6.19(\mathrm{Cl} 95 \% 1.50-25.48, p=0.0116)$ for high risk vs no risk and $3.0(\mathrm{Cl} 95 \% 0.98-9.19, p=0.0545)$ for intermediate risk vs no risk. Sensitivity of EZSCAN for early detection of these abnormalities in glucose tolerance was $77 \%$ while it was $14 \%$ for fasting plasma glucose and $66 \%$ for $\mathrm{HbA}_{1 \mathrm{c}}$.

Conclusions: Assessment of sudomotor function by EZSCAN, a sensitive method when compared with the conventional methods may be very useful to identify and manage subjects at risk for developing glucose intolerance.

Keywords: Sudomotor function; Prediabetes; Diabetes; Glucose intolerance; Small fiber neuropathy; EZSCAN

Abbreviations: NGT: Normal Glucose Tolerance; FSOGTT: Frequently Sampled Oral Glucose Tolerance Test; BMI: Body Mass Index; $\mathrm{AUC}_{\text {glucose }}$ : Area under the curve of glucose during FSOGTT (0$120 \mathrm{~min}) ; \mathrm{AUC}_{\text {insulin }}$ : Area under the curve of insulin during FSOGTT (0-120 min); OR: Odds Ratio; FPG: Fasting Plasma Glucose; IFG: Impaired Fasting Glucose; IGT: Impaired Glucose Tolerance; DM: Diabetes Mellitus; OGTT: Oral Glucose Tolerance Test; DC: Direct Current; PG: Plasma Glucose; HDL-C: High Density Lipoprotein Cholesterol; LDL-C: Low Density Lipoprotein Cholesterol

\section{Introduction}

The prevalence of type 2 diabetes and prediabetes i.e. impaired fasting glucose (IFG) and impaired glucose tolerance (IGT) is increasing in developed and developing countries [1]. Early identification and treatment of persons with prediabetes have the potential to reduce or delay the progression to diabetes [2-6].

Presently, diabetes and prediabetes are diagnosed by cutoff levels on the basis of blood glucose or $\mathrm{HbA}_{1 c}$ levels $[7,8]$. There is a need to diagnose subjects with high risk for diabetes at an earlier stage using a simple, non-invasive, sensitive, quick and inexpensive tool. Measurement of $\mathrm{AUC}_{\text {insulin }}$ or $\mathrm{AUC}_{\text {glucose }}$ during frequently sampled oral glucose tolerance test (FSOGTT) has been proposed for early diagnosis of people at risk $[9,10]$. Small autonomic fiber neuropathy results in decreased sudomotor response and atrophy of the sweat glands. It can begin early in prediabetes or metabolic syndrome $[11,12]$. The American Diabetes Association suggests that sudomotor function assessing small fiber status should be included in the diagnostic tests for the detection of neuropathies in diabetes [13]. However lack of simple and quick method has not allowed widespread use of the sudomotor function as a screening tool for diabetic neuropathies. EZSCAN, a new device recently developed to allow a precise evaluation of sweat gland function based on sweat chloride concentrations has been shown to detect sudomotor dysfunction in people with diabetes or prediabetes when compared to controls $[14,15]$.

The aim of this follow-up study performed in subjects classified as NGT by an initial OGTT was to determine and compare the performance of EZSCAN with $\mathrm{HbA}_{1 \mathrm{C}}$ and fasting plasma (FPG) to predict future abnormalities in $\mathrm{AUC}_{\text {glucose }}$ and $\mathrm{AUC}_{\text {insulin }}$ diagnosed during an FSOGTT performed 8 months later.

\section{Patients and Methods}

\section{Study population}

The study was done during January-July 2009 in 3 diabetes centers in Chennai, India. The study protocol, patient information details and informed consent form were approved by the Institutional Ethics Committee.

${ }^{*}$ Corresponding author: Jean-Henri Calvet, Impeto Medical, Medical Affairs, 17 rue Campagne Première, 75014 Paris, France, Tel: +33 1432016 40; Fax: +33 433518 33; E-mail: jean-henri.calvet@impeto-medical.com

Received March 16, 2011; Accepted April 04, 2011; Published April 06, 2011

Citation: Ramachandran A, Moses A, Snehalatha C, Shetty AS, Seeli AC, et al. (2011) Assessment of Sudomotor Function to Predict Future Abnormalities of Glucose Tolerance in at Risk Population. J Diabetes Metab 2:125. doi:10.4172/21556156.1000125

Copyright: (C) 2011 Ramachandran A, et al. This is an open-access article distributed under the terms of the Creative Commons Attribution License, which permits unrestricted use, distribution, and reproduction in any medium, provided the original author and source are credited. 
Subjects who were involved in a previous study and had NGT on initial OGTT (Time 0, T0) were asked to participate in an 8 months follow-up study [15]. Out of the 158 NGT subjects 69 (44\%) consented to participate and to undergo a FSOGTT in the 8 month follow-up study (Time 8 months, T8). Anthropometric measurements and blood pressure (once after $10 \mathrm{~min}$ rest in supine position) were recorded at T8 (Table 1).

\section{EZSCAN measurement}

The new EZSCAN ${ }^{\text {mix }}$ device (Impeto Medical, Paris, France) is designed to perform a precise evaluation of sweat gland function based on sweat chloride concentrations using reverse iontophoresis and chronoamperometry [14]. Measurements are performed where sweat glands are most numerous on the palms of the hands and soles of the feet. Large area nickel electrodes are used alternatively as an anode or a cathode and a direct current (DC) incremental voltage $\leq 4$ volts is applied on the anode. This DC through reverse iontophoresis induces a voltage on the cathode and generates a current (intensity of about $0.2 \mathrm{~mA}$ ) between the anode and the cathode, related to chloride concentration. At low active direct current, the stratum corneum of the skin constitutes an electrical barrier which prevents any other way of liquid extraction as shown in the Chizmadzhev model [16]. The electrochemical phenomena are measured by two active electrodes (the anode and the cathode) successively in the two regions, whilst the two other passive electrodes allow retrieval of the body potential. Contrarily to the methods based on impedancemetry used to evaluate the body composition, for example, in this method the current is a direct current and not an alternating one; it is based on an electrochemical reaction and not only on electrical properties.

The apparatus consists of two sets of electrodes for the hands and the feet, all of which are connected to a computer for recording and data management purposes (Figure 1). To conduct the test, the patients are required to place their hands and feet on the electrodes. The patients are then required to stand still for 2 minutes. During the test 6 combinations of 15 different low DC voltages are applied. No special patient preparation is required and a medical personnel training is short and easy. The data, namely electrochemical skin conductance (ESC) in hands and feet are displayed instantaneously on a standard PC computer in the form of a scale which classifies the subjects in three colors according to an increasing risk for impaired glucose metabolism (green, yellow, orange/red). The green color is defined as normal sudomotor function with no risk (scale $<50 \%$ ), the yellow color by a moderate disturbance in sudomotor function with an intermediate risk (scale 50-65\%); orange-red=high by a high disturbance in sudomotor function with a high risk (scale $>65 \%$ ). All data were analyzed by a person who was blinded to other data of the participants involved in the study.

\section{Laboratory assessment}

All 69 participants had FSOGTT [17] at T8 with measurement of glucose and insulin plasma levels following a $75 \mathrm{~g}$ glucose load. Their baseline demographic, anthropometric and biochemical characteristics (Table 1) were similar to that of subjects classified as NGT in the previous study and that did not want to be involved in this following study $(\mathrm{n}=89)$ [13]. Blood samples were drawn at 10 time points for 3 hours (15 min before, $0,10,25,45,75,100,120,150$ and $180 \mathrm{~min}$ after glucose intake). Plasma glucose and corresponding insulin values were measured in a central laboratory. Plasma glucose was measured by glucose-oxidase peroxidase method. Insulin was measured using chemiluminiscence Immunoassay (Centaur Kit, Advia Centaur) [18]. Based on glucose values of FSOGTT, subjects were classified as NGT (2h plasma glucose $(2 \mathrm{~h}-\mathrm{PG})<7.8 \mathrm{mmol} / \mathrm{l})$, IGT $(2 \mathrm{~h}-\mathrm{PG} \geq 7.8 \mathrm{mmol} / \mathrm{l}$ and $<11.0 \mathrm{mmol} / \mathrm{l})$

\begin{tabular}{|c|c|c|c|c|c|c|c|c|}
\hline \multirow{2}{*}{ FSOGTT 2h-PG } & \multicolumn{2}{|c|}{ Normal glucose tolerance } & \multicolumn{2}{|c|}{ Impaired glucose tolerance } & \multicolumn{2}{|c|}{ Diabetes Mellitus } & \multicolumn{2}{|c|}{ Total } \\
\hline & $n$ & $\%$ & $n$ & $\%$ & $n$ & $\%$ & $\mathrm{n}$ & $\%$ \\
\hline Normal & 33 & 62 & 1 & 9 & 0 & -- & 34 & 49 \\
\hline High AUC ${ }_{\text {insulin }}$ & 12 & 23 & 3 & 27 & 0 & -- & 15 & 22 \\
\hline High AUC ${ }_{\text {glucose }}$ & 8 & 15 & 7 & 64 & 5 & 100 & 20 & 29 \\
\hline Total & 53 & & 11 & & 5 & & 69 & \\
\hline
\end{tabular}

Table 1: Comparison between the 2h-PG for glucose tolerance (NGT, IGT and DM) and plasma insulin levels during FSOGTT (normal, high or low) performed at T8.

\begin{tabular}{|c|c|c|c|c|}
\hline & All $(n=69)$ & Normal $(n=34)$ & High AUC ${ }_{\text {insulin }}(n=15)$ & High AUC $_{\text {glucose }}(n=20)$ \\
\hline Gender, Male n (\%) & $32(46 \%)$ & $17(50 \%)$ & $8(53 \%)$ & $8(40 \%)$ \\
\hline AGE (yrs) & $42.0 \pm 9.0$ & $40.5 \pm 8.5$ & $41.5 \pm 10.3$ & $44.9 \pm 8.5$ \\
\hline BMI $\left(\mathrm{kg} \cdot \mathrm{m}^{-2}\right)$ & $28.1 \pm 5.0$ & $27.5 \pm 4.2$ & $26.6 \pm 3.9$ & $30.2 \pm 5.8$ \\
\hline $\mathrm{SBP}(\mathrm{mmHg})$ & $121.5 \pm 10.6$ & $119 \pm 11.9$ & $122.1 \pm 10.0$ & $125.6 \pm 7.6$ \\
\hline $\mathrm{DBP}(\mathrm{mmHg})$ & $79.6 \pm 6.4$ & $78.4 \pm 7.0$ & $79.1 \pm 6.1$ & $82.1 \pm 5.1$ \\
\hline FPG $(\mathrm{mmol} / \mathrm{l})^{\star} \#$ & $4.2 \pm 0.8$ & $4.2 \pm 0.7$ & $4.9 \pm 0.9$ & $4.1 \pm 0.9$ \\
\hline $2 \mathrm{~h}-\mathrm{PG}(\mathrm{mmol} / \mathrm{l})^{*}$ & $5.6 \pm 1.8$ & $5.5 \pm 0.9$ & $5.6 \pm 0.9$ & $5.8 \pm 0.9$ \\
\hline $\mathrm{HbA}_{1 \mathrm{C}(\%)}{ }^{*} \#$ & $5.9 \pm 0.5$ & $5.7 \pm 0.4$ & $5.7 \pm 0.5$ & $6.2 \pm 0.6^{a}$ \\
\hline Total cholesterol* mg/dl & $192.1 \pm 32.5$ & $186 \pm 32.1$ & $189 \pm 37.5$ & $204.5 \pm 27.1$ \\
\hline $\mathrm{HDL}-\mathrm{C}^{*} \mathrm{mg} / \mathrm{dl}$ & $44.2 \pm 9.1$ & $43.9 \pm 9.1$ & $41.6 \pm 11.7$ & $46.6 \pm 6.4$ \\
\hline LDL-C* mg/dl & $123.7 \pm 32.4$ & $115.6 \pm 34$ & $125.3 \pm 30.8$ & $136.1 \pm 27.9$ \\
\hline Triglycerides* mg/dl & $153.6 \pm 85.5$ & $150.6 \pm 82.4$ & $146.7 \pm 87.6$ & $163.9 \pm 92.5$ \\
\hline $1^{\text {st }}$ degree family history of diabetes $\mathrm{n}(\%)$ & $63(91 \%)$ & $30(88 \%)$ & $13(87 \%)$ & $20(100 \%)$ \\
\hline
\end{tabular}

\# $\mathrm{p}<0.05$ for global comparison

${ }^{*}$ Measurements performed at T0 (all other measurements were performed at T8)

Normal: $\mathrm{AUC}_{\text {glucose }}<960 \mathrm{mmol} / \mathrm{l} . \mathrm{mn}$ and $\mathrm{AUC}_{\text {insulin }}<=75500 \mathrm{pmol} / \mathrm{l} . \mathrm{mn} ;$ High isolated $\mathrm{AUC}_{\text {glucose }}>=960 \mathrm{mmol} / \mathrm{I} . \mathrm{mnl}$ and $\mathrm{AUC}$ insulin $<=75500 \mathrm{pmol} / \mathrm{I} . \mathrm{mn}$; High AUC $\mathrm{H}_{\text {insuli }}>$

$75500 \mathrm{pmol} / \mathrm{l} . \mathrm{mn}$

a - Compared with normal

Table 2: Characteristics of patients at T0 and T8 classified according to plasma insulin and glucose during FSOGTT at T8. 


\begin{tabular}{|l|l|l|l|l|l|l|}
\hline \multirow{2}{*}{$\begin{array}{l}\text { EZSCAN score } \\
\text { at T0 }\end{array}$} & \multicolumn{4}{l|}{ EZSCAN score at T8 } & FSOGTT at T8 \\
\cline { 2 - 7 } & $>65 \%$ & $50-65 \%$ & $<50 \%$ & High AUC $_{\text {gluocse }}$ or AUC $_{\text {insulin }}$ & Normal \\
\hline$>65 \%$ & 15 & 15 & 0 & 0 & 11 & 4 \\
\hline $50-65 \%$ & 28 & 10 & 14 & 4 & 21 & 7 \\
\hline$<50 \%$ & 26 & 6 & 9 & 11 & 8 & 18 \\
\hline
\end{tabular}

Table 3: Results of EZSCAN follow-up.

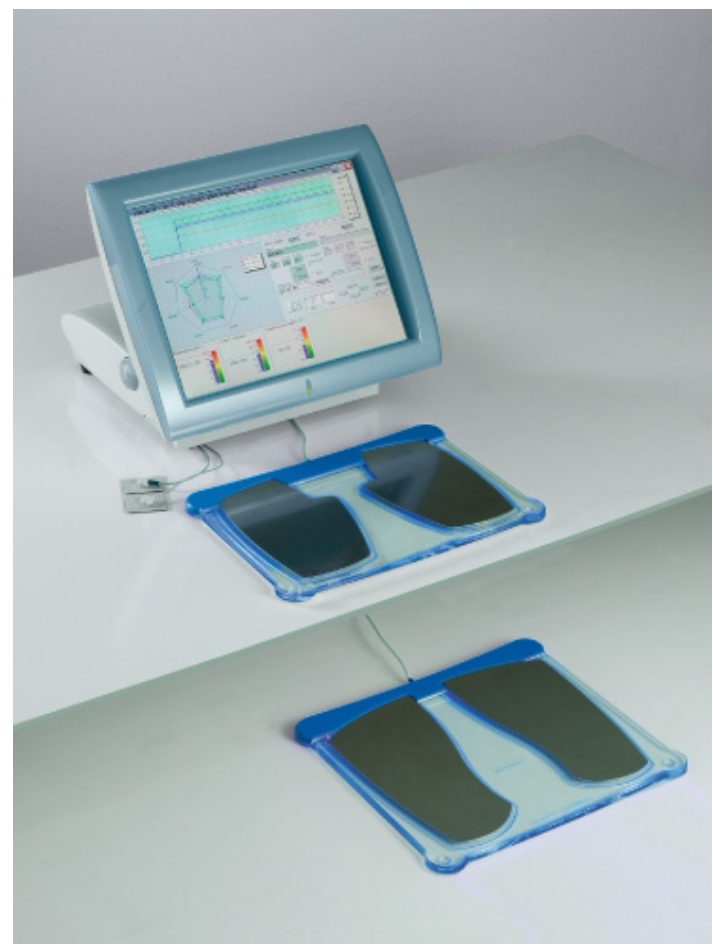

Figure 1: General presentation of EZSCAN. Hands and feet electrodes with the master unit. Subjects are only requested to stay in standing position during 2 min with palm of the hands and sole of the feet in contact with the electrodes.

or diabetes mellitus (DM) (fasting plasma glucose (FPG) $>7 \mathrm{mmol} / \mathrm{l}$ and/or $2 \mathrm{~h}-\mathrm{PG} \geq 11.0 \mathrm{mmol} / \mathrm{l})$. According to glucose and insulin $\mathrm{AUC}_{0}$ as measured during FSOGTT (area under the curve between 0 and $120 \mathrm{~min}$ ), subjects were classified in three groups: normal $\left(\mathrm{AUC}_{\text {glucose }}\right.$ $<960$ and $\left.\mathrm{AUC}_{\text {insulin }}<=75500\right)$, high $\mathrm{AUC}_{\text {insulin }}\left(\mathrm{AUC}_{\text {insulin }}>75500\right)$ or high isolated $\mathrm{AUC}_{\text {insulin }}\left(\mathrm{AUC}_{\text {lucose }} \geq 960\right.$ and $\left.\mathrm{AUC} \mathrm{insuin}_{\text {insulin }} \leq 75500\right) . \mathrm{HbA}_{1 \mathrm{C}}$ was measured at T0 by HPLC (BIORAD). Fasting serum lipids (total cholesterol, triglycerides, high-density lipoprotein cholesterol (HDL-C) and low-density lipoprotein cholesterol (LDL-C) were measured at T0 by standard enzymatic procedures.

\section{Statistical analyses}

Results for quantitative variables are shown as mean \pm SD. Group means were compared by analysis of variance. Chi-square test was used for the comparisons of proportions. Logistic regressions were used to analyse the relation between the $2 \mathrm{~h}-\mathrm{PG}$ and the different levels of FSOGTT diagnosis at T8. The fit of the model was good and convergence criteria were met. As a rule, a p-value $<0.05$ was regarded as statistically significant. The statistical analysis was done using R 2.9.2 with ROCR package $[19,20]$.

\section{Results}

Among the 69 subjects all NGT at T0, 11 were classified as IGT and 5 as patients with diabetes according to the FSOGTT at T8 (Table 1). Among the 53 subjects still classified as NGT at T8, 12 had high $\mathrm{AUC}_{\text {insulin }}$ and 8 had high isolated $\mathrm{AUC}_{\text {glucose }}$ during FSOGTT (Table 1).

None of the three most widely used parameters to screen for diabetes (FPG, $\mathrm{HbA}_{1 \mathrm{c}}, 2 \mathrm{~h}-\mathrm{PG}$ ) was significantly different between patients with normal or high $\mathrm{AUC}_{\text {insulin }}$ groups, while only FPG and $\mathrm{HbA}_{1 \mathrm{c}}$ values were significantly higher in patients with high $\mathrm{AUC}_{\text {glucose }}$ when compared to normal (Table 2). There was no significant difference in $2 \mathrm{~h}-\mathrm{PG}$ values between the 3 groups.

Comparing the results of the EZSCAN at T0 with the FSOGTT at T8, $81 \%$ of the subjects with an abnormal $2 \mathrm{~h}-\mathrm{PG}$ (11 with impaired glucose tolerance and 5 with diabetes) had a score $>50 \%$. Therefore, the sensitivity of EZSCAN to detect future IGT or diabetes according to $2 \mathrm{~h}-\mathrm{PG}$ performed 8 months later was $81 \%$. Among the 26 subjects with a EZSCAN score $<50 \%$ at T0, $88 \%$ were still NGT according to the $2 \mathrm{~h}-\mathrm{PG}$ at $\mathrm{T} 8.73 \%$ of the 15 subjects with score $>65 \%$ had high $\mathrm{AUC}_{\text {glucose }}$ or high $\mathrm{AUC}_{\text {insulin }} 8$ months later while $69 \%$ of the subjects with $<50 \%$ reading had normal $\mathrm{AUC}_{\text {glucose }}$ or $\mathrm{AUC}_{\text {insulin }}$ (Table 3). The Odds Ratios (OR) to have high $\mathrm{AUC}_{\text {glucose }}$ or high $\mathrm{AUC}_{\text {insulin }} 8$ months later in the different EZSCAN classification groups were 6.19 for orange + red vs green (CI 95\% $1.50-25.48, \mathrm{p}=0.0012)$, and 3.0 for yellow vs. green (CI 95\% $0.98-9.19, \mathrm{p}=0.055)$.

The diagnostic sensitivity for predicting high $\mathrm{AUC}_{\text {glucose }}$ or high $\mathrm{AUC}_{\text {insulin }}$ from FSOGTT 8 months later for EZSCAN (cut off $50 \%$ on the scale), FPG $(>5.6 \mathrm{mmol} / \mathrm{l})$, and $\mathrm{HbA}_{1 \mathrm{c}}(>5.7 \%)$ were $77 \%, 14 \%$ and $66 \%$ respectively while the corresponding specificities were $53 \%, 94 \%$ and $41 \%$.

\section{Discussion}

This prospective study performed in subjects classified as NGT by an initial OGTT showed that EZSCAN, a simple noninvasive test for assessment of sudomotor function was able to predict IGT or DM 8 months later with a sensitivity of $81 \%$. Its sensitivity to predict high values for $\mathrm{AUC}_{\text {glucose }}$ or $\mathrm{AUC}_{\text {insulin }}$ was $77 \%$ while it was $14 \%$ and $66 \%$ for FPG or $\mathrm{HbA}_{1 \mathrm{c}}$.

The high conversion rate of NGT subjects to IGT or DM: 16 out of 69 subjects $(23 \%)$ observed in a short period of 8 months might be explained by the fact that south Asians have rapidly rising prevalence of diabetes [21,22]. Indian Diabetes Prevention Programme - 1 (IDPP1) had shown a rapid conversion rate for IGT to diabetes in 3 years, in control subjects without intervention [5]. It can be also explained by the recruitment of subjects from diabetes centers. More than $90 \%$ of the participants had $1^{\text {st }}$ degree family history of diabetes: with a high risk for diabetes they could have sought medical check-up in these centres.

The classification for EZSCAN at T0 in these subjects that were all NGT was first compared with the fasting or $2 \mathrm{~h}-\mathrm{PG}$ results of the OGTT at T8. The glucose tolerance assessment has been shown to be a non reproducible test with low sensitivity for assessing the evolution of diabetes [23]. As high values in $\mathrm{AUC}_{\text {olucose }}$ or $\mathrm{AUC}_{\text {insulin }}$ precede the occurrence of abnormalities detectable by classical glucose tolerance tests it seems important to compare EZSCAN results at T0 to $\mathrm{AUC}_{\text {glucose }}$ or $_{\mathrm{AUC}_{\text {insulin }}}$ at T8 $[24,25]$. Disturbances in sudomotor dysfunction were evidenced at T0 while low modification was observed in FPG or $\mathrm{HbA}_{1 \mathrm{C}}$. When compared to EZSCAN sensitivity of FPG to predict further disturbance in $\mathrm{AUC}_{\text {glucose }}$ or $\mathrm{AUC}_{\text {insulin }}$ was low with high specificity, while sensitivity and specificity of $\mathrm{HbA}_{1 \mathrm{C}}$ were a little smaller. Several studies performed with different methods have shown that sudomotor dysfunction due to small-fiber injury may develop early in diabetes and can be detected even in persons with IGT $[11,12]$. Neural impairment 
Citation: Ramachandran A, Moses A, Snehalatha C, Shetty AS, Seeli AC, et al. (2011) Assessment of Sudomotor Function to Predict Future Abnormalities of Glucose Tolerance in at Risk Population. J Diabetes Metab 2:125. doi:10.4172/2155-6156.1000125

in IGT is mainly subclinical, asymptomatic characterized by small fiber neuropathy not detected by the classical methods used to explore neuropathy that assess large-fiber dysfunction [12].

The number of subjects tested in the study is small explaining the large $\mathrm{CI}$ of OR to develop abnormal $\mathrm{AUC}_{\text {insulin }}$ or $\mathrm{AUC}_{\text {glucose }}$ in the EZSCAN risk classification groups. This is a pilot study conducted in a small number of patients and in a high risk ethnic population. Larger prospective studies with longer follow-up will help to ascertain the utility of this simple and easily repeatable method as a screening tool before long and invasive procedures like FSOGTT.

The early identification of subjects at risk of glucose intolerance and abnormalities in insulin or glucose response in FSOGTT by a quick method, easily understandable by the patient thanks to color risk classification can provide an opportunity to start an early intervention with lifestyle modifications to prevent diabetes and cardiovascular diseases.

\section{References}

1. Eds.Unwin N, Whiting D, Gan D, Jacqmain O, Ghyoot (2009) International Diabetes Federation G. DiabetesAtlas, 4th Edition.

2. Knowler WC, Barrett-Connor E, Fowler SE, Hamman RF, Lachin JM, et al. (2002) Diabetes Prevention Program Research Group. Reduction in the incidence of type 2 diabetes with lifestyle intervention or metformin. N Engl J Med 346: 393-403.

3. Lindström J, llanne-Parikka P, Peltonen M, Aunola S, Eriksson JG, et al. (2006) Finnish Diabetes Prevention Study Group. Sustained reduction in the incidence of type 2 diabetes by lifestyle intervention: follow-up of the Finnish Diabetes Prevention Study. Lancet 368: 1673-1679.

4. Li G, Zhang P, Wang J, Gregg EW, Yang W, et al. (2008) The long-term effect of lifestyle interventions to prevent diabetes in the China Da Qing Diabetes Prevention Study: a 20-year follow-up study. Lancet 371: 1783-1789.

5. Ramachandran A, Snehalatha C, Mary S, Mukesh B, Bhaskar AD, et al. (2006) The Indian Diabetes Prevention Programme shows that lifestyle modification and metformin prevent type 2 diabetes in Asian Indian subjects with impaired glucose tolerance (IDPP-1). Diabetologia 49: 289-297.

6. Gillies CL, Abrams KR, Lambert PC, Cooper NJ, Sutton AJ, et al. (2007) Pharmacological and lifestyle interventions to prevent or delay type 2 diabetes in people with impaired glucose tolerance: systematic review and metaanalysis. BMJ 334: 299

7. World Health Organization. Definition, Diagnosis and Classification of Diabetes Mellitus and its complication (1999) Part 1: Diagnosis and Classification of Diabetes Mellitus WHO/NCD/NCS/99.2 Geneva: World Health Organization.

8. Kilpatrick ES, Bloomgarden ZT, Zimmet PZ (2009) International Expert Committee Report on the role of the A1C assay in the diagnosis of Diabetes The international expert committee. Diabetes Care 32: e159-e160.
9. Abdul-Ghani AM, Williams K , Defronzo RA, Stern M (2007) What Is the Best Predictor of Future Type 2 Diabetes? Diabetes Care 30: 1544-1548.

10. McKeigue PM, Pierpoint T, Ferrie JE, Marmot MG (1992) Relationship of glucose intolerance and hyperinsulinaemia to body fat pattern in south Asians and Europeans. Diabetologia 35: 785-791.

11. Vinik A, Maser RA, Ziegler D (2010) Neuropathy: The crystal ball for cardiovascular disease. Diabetes Care 33: 1688-1690

12. Mayaudon H, Miloche PO, Bauduceau B (2010) A new simple method to assess sudomotor function: interest in type diabetes. Diabetes \& Metabolism 36: $450-454$

13. Ramachandran A, Moses A, Shetty S, Thirupurasundari CJ, Seeli AC, et al (2010) A new non-invasive technology to screen for dysglycemia including diabetes. Diabetes Res. Clin. Pract 88: 302-306.

14. Chizmadzhev YA, Indenbom AV, Kuzmin PI, Galichenko SV, Weaver JC, et al. (1998) Electrical properties of skin at moderate voltages: contribution of appendageal macropores. Biophysical Journal 74: 843-856.

15. Dalla Man C, Campioni M, Polonsky KS, Basu R, Rizza RA, et al. (2005) Two hour seven-sample oral glucose tolerance test and meal protocol: minimal model assessment of beta-cell responsivity and insulin sensitivity in nondiabetic individuals. Diabetes 54: 3265-3273.

16. Manley SE, Stratton IM, Clark PM, Luzio SD (2007) Comparison of 11 Human Insulin Assays: Implications for Clinical Investigation and Research. Clinical Chemistry 53: 922-932

17. Metz CE (1978) Basic principles of ROC analysis. Semin Nucl Med 8: 283-298.

18. Sing T, Sander O, Beerenwinkel N, Lengauer T (2005) ROCR: visualizing classifier performance in R. Bioinformatics 21: 3940-3941.

19. Ramachandran A, Mary S, Yamuna A, Murugesan N, Snehalatha C (2008) High prevalence of diabetes and cardiovascular risk factors associated with urbanization in India. Diabetes Care 31: 893-898.

20. Ramachandran A, Ma RC, Snehalatha C (2010) Diabetes in Asia. Lancet 375 408-418.

21. Yudkin JS, Alberti KG, McLarty DG, Swai AB (1990) Impaired glucose tolerance. BMJ 301: 397-402.

22. Snehalatha C, Mary S, Selvam S, Sathish Kumar CK, Shetty SB, et al (2009) Changes in insulin secretion and insulin sensitivity in relation to the glycemic outcomes in subjects with impaired glucose tolerance in the Indian Diabetes Prevention Programme-1 (IDPP-1). Diabetes Care 32: 1796-1801.

23. Abdul-Ghani MA, Abdul-Ghani T, Ali N, Defronzo RA (2008) One-hour plasma glucose concentration and the metabolic syndrome identify subjects at high risk for future type 2 diabetes. Diabetes Care 31: 1650-1655

24. Sumner CJ, Sheth S, Comblath DR, Polydefks M (2003) The spectrum of neuropathy in diabetes and impaired glucose tolerance. Neurology 60: 108-111.

25. Putz Z, Tabák AG, Tóth N, Istenes I, Németh N, et al. (2009) Noninvasive evaluation of neural impairment in subjects with impaired glucose tolerance. Diabetes Care 32: 181-183. 